\title{
A new look at the heart in diabetes mellitus: from ailing to failing
}

\author{
E.Standl, O.Schnell \\ Diabetes Research Institute Munich, Munich-Schwabing, Munich, Germany
}

\section{Abstract}

This review discusses some of the mechanisms inherent in diabetes that predispose patients to increased cardiac morbidity and mortality.

Single photon emission computerized tomography or photon emission tomography with radioactive labeled analogues of norepinephrine have shown that cardiac sympathetic dysfunction and incompetence are early and also late abnormalities in patients with Type I (insulin-dependent) and Type II (non-insulindependent) diabetes mellitus. Furthermore, myocardial blood flow assessment with photon emission tomography has shown that in patients without myocardial perfusion deficits, endothelial-dependent vasodilatation is severely reduced in relation to cardiac sympathetic dysfunction. In addition, signs of endothelial activation have also been found early in patients with Type I and Type II diabetes in whom vascular disease has not been clinically detected. This activation in conjunction with glycaemic control is important in determining macrovascular mortality. Car- diac sympathetic dysfunction is partially restored to normal with near normalisation of glycaemia.

Interpretations. Recently unrecognized "subtle" changes predispose the heart to failure, after ischaemia-induced remodelling, and arteriosclerotic plaques to instability and rupture. These changes act in conjunction with effects, driven by hyperglycaemia and diabetes, on the endothelium of large blood vessels, e.g. on nitric oxide release or on protein kinase$\mathrm{C} \beta$ activation. Meticulous glucose control early on and rapid recompensation of hyperglycaemia in patients with acute coronary syndrome are part of a successful intensive multifactorial approach to prevent the heart in diabetes converting from ailing to failing. [Diabetologia (2000) 43: 1455-1469]

Keywords Cardiac sympathetic dysfunction, autonomic neuropathy, coronary blood flow reserve, endothelial activation, congestive heart failure, nitric oxide, protein kinase $\mathrm{C}$, acute coronary syndrome, myocardial infarction.
Corresponding author: Dr. E. Standl, Diabetes Research Institute Munich and $3^{\text {rd }}$ Medical Department, Academic Hospital Munich-Schwabing, Kölner Platz 1, D-80804 Munich, Germany

$14^{\text {th }}$ Camillo Golgi Lecture given during the $35^{\text {th }}$ Annual Meeting of the EASD, Brussels, September 1999

Abbreviations: ACS, Acute coronary syndrome; NO, nitric oxide; VEGF, vascular endothelial growth factor; MIBG, metaiodobenzylguanidine; SPECT, single-photon emission tomography; PET, positron emission tomography; PKC, protein kinase C; ATPase, adenosine tri- phophatase; ACE, angiotensin converting enzyme; HED, hydroxyephedrine; MONICA, Monitoring of Trends and Determinants in Cardiovascular Diseases; PTCA, precutaneous transluminal coronary angioplasty.
Mortality among diabetic patients with acute coronary syndrome (ACS) and other heart diseases has remained high despite the increasing availability and application of interventive cardiological and cardiosurgical therapy in recent years [1-6]. Cardiac mortality seems to be on the rise in diabetic patients [7] [probably both in patients with Type I (insulin-dependent) and Type II (non-insulin-dependent) diabetes mellitus] and responsible for nearly every other premature death of the millions of people with diabetes in the Western world [8-10]. It has therefore been speculated for years that the diabetic heart has inherent abnormalities which although poorly understood determine to a large extent the poor outcome of dia- 
Table 1. Increased restenosis in diabetic compared with non-diabetic patients both after PTCA and stent implantation

\begin{tabular}{|c|c|c|c|c|c|c|}
\hline & \multirow[t]{2}{*}{ Intervention } & \multicolumn{2}{|l|}{$n$} & \multicolumn{3}{|c|}{$\%$ patients with restenosis } \\
\hline & & $\mathrm{D}$ & ND & $\mathrm{D}$ & ND & $p$ \\
\hline Stein et al. [19] & PTCA & 1133 & 9300 & 25 & 21 & $<0.001$ \\
\hline Van Belle et al. [21] & PTCA & 57 & 243 & 63 & 36 & $<0.002$ \\
\hline Van Belle et al. [21] & Stent & 56 & 244 & 25 & 27 & NS \\
\hline Carozza et al. [23] & Stent & 40 & 190 & 55 & 20 & $<0.001$ \\
\hline Kastrati et al. [24] & Stent & 134 & 715 & 40 & 24 & $<0.001$ \\
\hline
\end{tabular}

$\mathrm{D}=$ diabetic, $\mathrm{ND}=$ non-diabetic

betic patients [11-14]. Specific vascular, neuropathic and myopathic alterations have been suggested as being responsible for the excessive cardiovascular morbidity and mortality in diabetes [11-14].

\section{Epidemiological background and natural course}

A large and growing body of epidemiological data strongly suggests a link between diabetes and cardiovascular complications [2, 3, 8, 9, 10,13]. It is well established that compared with the general population the prevalance of cardiac death is increased two to threefold in men with diabetes and in excess of fivefold in women with the disease $[8,9,13]$. A recent study has even found that the risk of cardiac death in Type II diabetic patients, from the diabetes alone, is as high as in non-diabetic patients with a previous myocardial infarction being approximately $20 \%$ over 10 years [15]. The presence of a previous myocardial infarction in diabetic patients raises the mortality rate up to $60 \%$ over 10 years [15]. It is no surprise therefore that life expectancy from the time of clinical diagnosis of Type II diabetes is reduced by $30 \%$ [16]. Like other studies the German MONICA (Monitoring of Trends and Determinants in Cardiovascular Diseases) project in Augsburg found that the prevalence of Type II diabetes is much higher in adults who suffer from ACS than in the general population [17]. This was true of all age groups and both sexes. Among elderly men (aged 65-74 years), approximately $30 \%$ of those who had ACS had Type II diabetes, whereas only $12 \%$ of men in the general population of this age group had Type II diabetes. Among elderly women (aged 65-74 years), the difference was even greater. Over $40 \%$ of those with ACS also had Type II diabetes, in contrast to only $12 \%$ of the general population in this age group [17].

There seems to be little progress in mid-term survival of diabetic compared with non-diabetic patients with ACS as indicated from the German MONICA project and other studies. In the Augsburg registry, for example, survival rates of non-diabetic men have improved considerably in more recent years, probably associated with the wider use of newer treatments i.e. thrombolysis, percutaneous transluminal coro- nary angioplasty (PTCA), beta-blocker and angiotensin converting enzyme (ACE)-inhibitor therapy $[1,17]$. Comparison of the numbers of non-diabetic men who survived for at least 28 days after ACS during the years 1985 to 1988 with those who survived during the period 1989 to 1992 showed the 5 year mortality rate (Kaplan-Meier life-table analysis) had dropped from 21 to $13 \%$, in contrast to the diabetic cohorts, where the 5 year death rate remained unchanged and excessively high with $37 \%$ in both periods [17]. Similar discrepancies between non-diabetic as opposed to diabetic patients with advanced cardiovascular disease were seen when the outcome after interventive treatment was evaluated in the nineties, e.g. after thrombolysis, PTCA, stenting (Table 1), use of abciximab and also cardiac by-pass surgery [1, 18, 19, 20-25, 26-29]. Reocclusion, another myocardial infarction, and death are much more common in the diabetic patients and suggest that mere revascularisation procedures are not sufficiently effective for the diabetic heart [18-30].

The short-term outcome of diabetic patients with ACS seems to be even worse. In the German MONICA survey, $28 \%$ of diabetic compared with $16 \%$ of non-diabetic patients died on the first day of hospital admission and 6 compared with $4 \%$ between day 2 and 28 [17]. Thus, together with the $34 \%$ of deaths before hospital admission both in the diabetic and the non-diabetic group of patients, only a third of the diabetic subjects survived a first myocardial infarction, whereas half of the non-diabetic patients are still alive 28 days afterwards [17]. This is in line with many other studies [3-7].

Overall, cardiac death is the main determinant of life expectancy in Type I and Type II diabetic patients $[2,3,9,10,13]$. It is the presence of diabetic nephropathy, which excessively increases the cardiovascular risk in diabetic patients [31,32] and a cluster of risk factors, including high blood pressure, dyslipidaemia and a prothrombotic dysbalance, that contributes to impaired cardiac performance [3, 13, 25, 33]. For a long time the natural course of the diabetic heart had seemed to be resistent to therapeutic improvement and it was not until the $1990 \mathrm{~s}$, that several intervention trials established the principal potential for reducing the high cardiovascular morbidity and mor- 
Diabetes, no diabetes (unadjusted)

Adjusted for clinical variables

Adjusted for angiographic variables

Adjusted for clinical \& angiographic variables

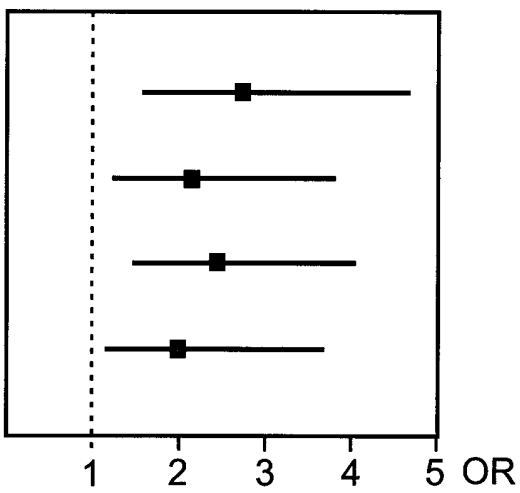

Fig. 1. The effect of diabetes on 30-day mortality after myocardial infarction in GUSTO-I in various modes of adjustment (reprinted with permission from the American College of Cardiology [6])

tality. Studies such as the UKPDS [33, 34], HOT study [35] and the Syst-Eur trial [36, 37] have shown the enormous effect of lowering blood pressure on the cardiovascular outcome of diabetic patients [3337]. In addition, the HOPE study showed a specific benefit of the ACE inhibitor, ramipril [38, 39]. The $4 \mathrm{~S}$ [40] and other statine-based intervention trials [41] strongly suggested a positive effect of LDL-cholesterol lowering as a secondary intervention in diabetic patients with ACS [40, 41]. Finally, the use of acetylsalicylic acid was also instrumental in reducing cardiovascular events in diabetic patients [35].

\section{Clinical characteristics responsible for poorer outcome}

It has often been suspected that the poorer outcome of diabetic patients with ACS is either due to a more pronounced accumulation of the classic cardiovascular risk factors, such as hypercholesterolaemia, smoking and hypertension $[6,10,12]$, or to withholding more modern treatment modalities, such as thrombolysis or beta-blocker therapy $[12,13]$. Others have thought that larger infarcts in the context of more severe and widely distributed atherosclerosis of the coronary artery system are responsible for the excessive mortality of diabetic subjects with ACS [3-6]. There is little published evidence to substantiate these notions $[1,5,6,42,43,44]$. An overview of studies dur- ing the last decade is given in Table 2. Serum cholesterol concentrations and, when available, LDL cholesterol concentrations are no different between diabetic and non-diabetic subjects with ACS (Table 2). The information provided for serum triglycerides and HDL cholesterol is often insufficient and might show a more adverse dyslipidaemic pattern with small dense LDL in diabetic patients. The percentage of active smokers is almost consistently lower in the diabetic compared with the non-diabetic cohorts with ACS. Even for hypertension and blood pressure several studies show no difference between the diabetic and the non-diabetic groups, but more studies do so. Infarct size, measured by peak creatine kinase, was not larger in diabetic patients with even an indication of smaller infarcts in diabetic patients in some instances. The frequency of angina pectoris before infarction was not decreased in diabetic patients when it was recorded (despite the probability of coexisting cardioneuropathy in diabetes) and the mean global ejection fraction in acute myocardial infarction was the same in the diabetic as in the non-diabetic group. When, as in GUSTO I [16], all conceivable clinical and coronary angiografic variables were adjusted for, a doubling of 30-day mortality after myocardial infarction remained unexplained in the diabetic group (Fig.1). Although much has been speculated about different treatment modalities between diabetic and non-diabetic patients with ACS, the Augsburg MONICA registry gives no clear-cut evidence for not applying modern treatment options such as thrombolysis, PTCA, beta-blocker therapy, to the same extent to diabetic patients [1].

Most striking in the diabetic patients with ACS is the excessively increased risk of left ventricular heart failure compared with non-diabetic patients $[5,6,18$, 42]. The occurrence of congestive heart failure in myocardial infarction determines to a large degree the early mortality. A fourfold increased rate of left ventricular failure was observed in diabetic patients, especially originating from medium sized infarcts, which have a good prognosis in non-diabetic patients [45].

Table 2. Similar risk profile of diabetic vs nondiabetic patients with acute myocardial infarction (acute coronary syndrome)

\begin{tabular}{lllllll}
\hline & $\begin{array}{l}\text { Löwel } \\
\text { et al. [1] }\end{array}$ & $\begin{array}{l}\text { Orlander } \\
\text { et al. [5] }\end{array}$ & $\begin{array}{l}\text { Woodfield } \\
\text { et al. [6] }\end{array}$ & $\begin{array}{l}\text { Fava } \\
\text { et al. [42] }\end{array}$ & $\begin{array}{l}\text { Meier } \\
\text { et al. [43] }\end{array}$ \\
\hline (LDL) cholesterol & $=$ & $=$ & $=$ & $=$ & $=$ & $=$ \\
Smoker & D $\downarrow$ & D $\downarrow$ & $=$ & D $\downarrow$ & D $\downarrow$ & $=$ \\
Blood pressure & D & D $\uparrow$ & D $\uparrow$ & $=$ & D $\uparrow$ & $=$ \\
Previous angina & n.r. & $=$ & n.r. & D $\uparrow$ & $=$ & $=$ \\
Peak CK & D $\downarrow$ & $=$ & n.r. & n.r. & n.r. \\
Global ejection fraction & n.r. & $=$ & $=$ & n.r. & $=$ \\
\hline
\end{tabular}

= equal risk; $\mathrm{D} \uparrow$ more risk, $\mathrm{D} \downarrow$ less risk in the diabetic groups, n. r. not recorded 


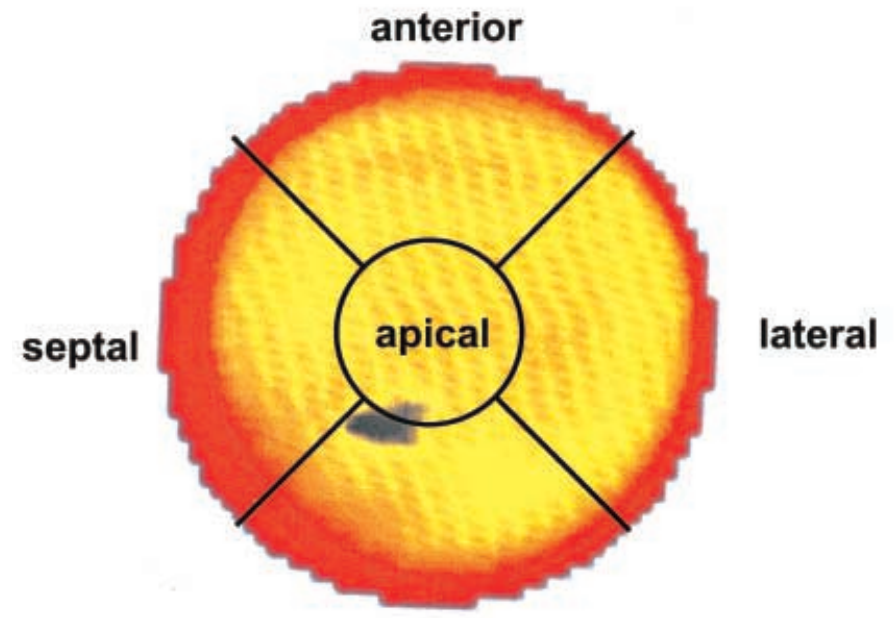

A

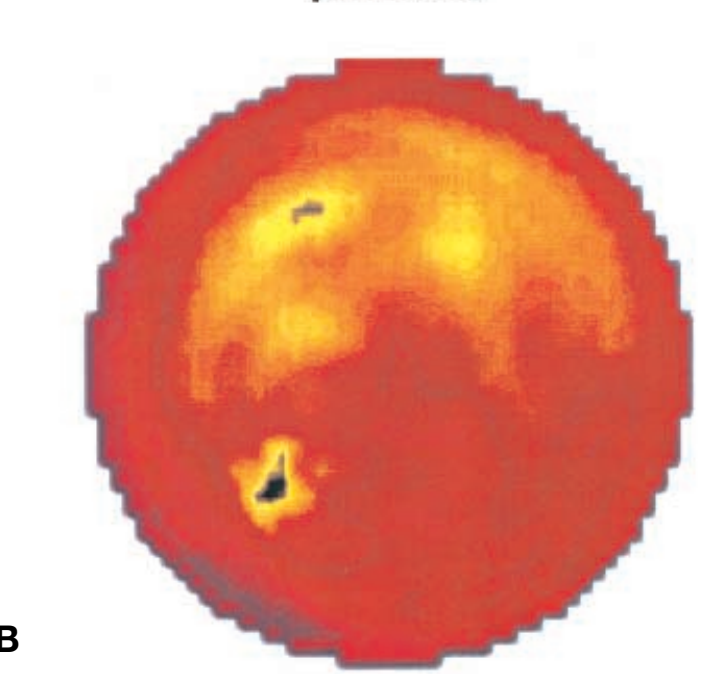

Fig. 2 A, B. Polar maps of myocardial 123-I-MIBG uptake in a control subject with uniform and homogeneous uptake (A) and a Type I diabetic patient with a severe reduction of uptake (B)

\section{Factors contributing to disordered cardiac remodelling}

Infarction-induced remodelling of the heart leads within hours to ventricular distension and dilatation and activates in particular the non-infarcted area through neurohumoral stimulation thus inducing a more stable hypertrophy and dilatation of the remaining unscarred ventricle tissue. This remodelling process is possibly hampered in diabetes, especially in a state of metabolic decompensation, for a number of reasons $[6,12,18,44]$.

1) Heart muscle metabolism seems to be critically dependent on the use of glucose during ischaemia [12]. Echocardiographic investigations show a rapid improvement of heart muscle performance when glucose uptake is stimulated by insulin injection in diabetic patients with ischaemic heart disease [46]. On the contrary, abundant concentrations of non-esteri- fied fatty acids might weaken cardiac pump function and, in addition, induce severe arrhythmias [47].

2) Blood flow and in particular reactive hyperaemia induced by hypoxia could be impaired even in the absence of advanced atherosclerosis in view of profound endothelial dysfunction but also activation both of which seem to occur quite early on in diabetes [12]. A decreased release of vasodilatory nitric oxide, an increased generation of vasoconstrictive endothelin 1 and an increased liberation of von Willebrand factor protein seem to be molecular pathobiological hallmarks of endothelial dysfunction and activation in diabetes (see below).

3) Diastolic dysfunction is a well-established (echocardiografic) abnormality in diabetes, probably in the context of hypertension and perhaps cardiomyopathy leading to a disordered filling of the left ventricle [11-14]. Quantitative and qualitative changes of the extracellular matrix formation of the heart have been observed dependent upon hyperglycaemia and an excess of glucose in animal and in vitro studies and could also play a part in humans.

4) A key problem in ischaemia-induced neurohumoral activation is the often unrecognized cardiac sympathetic dysfunction and incompetence (see below) [48-51]. Electrocardiogram-based tests for cardioneuropathy can be perfectly normal inspite of profound deficits in the cardiac sympathetic nervous system, in particular in the posterior, more distal region, which become apparent when radioactive labelled analogues of norepinephrine and single-photon or positron emission tomography are applied, (Fig.2 and below). Although there may be proximal hyperinnervation [52] and resting tachycardia [53], reactive neurohumoral activation during ischaemia can be severely blunted in many diabetic hearts, especially in the periphery, fostering thus impairment of left ventricular function and conversion to congestive heart failure. When performance of the myocardium after infarction has been evaluated, poor function of the non-infarct zone in the diabetic patients was a consistent finding $[6,18]$ and a considerably larger end-diastolic volume was needed than for the same ejection fraction of non-diabetic patients [44]. It cannot be excluded that this sympathetic resistance of the diabetic heart occurs secondary to some other prevailing deficit in cardiac or vascular function and is even a protective mechanism early in diabetes when circulating catecholamine concentrations are high. Nevertheless in ACS it evidently has negative implications for myocardial contractility and myocardial perfusion mediated by nitric oxide, leading to cardiac sympathetic incompetence. Sympathetic incompetence seems to be a key factor causing the heart in diabetes to turn from ailing to failing. Figure 3 summarises 


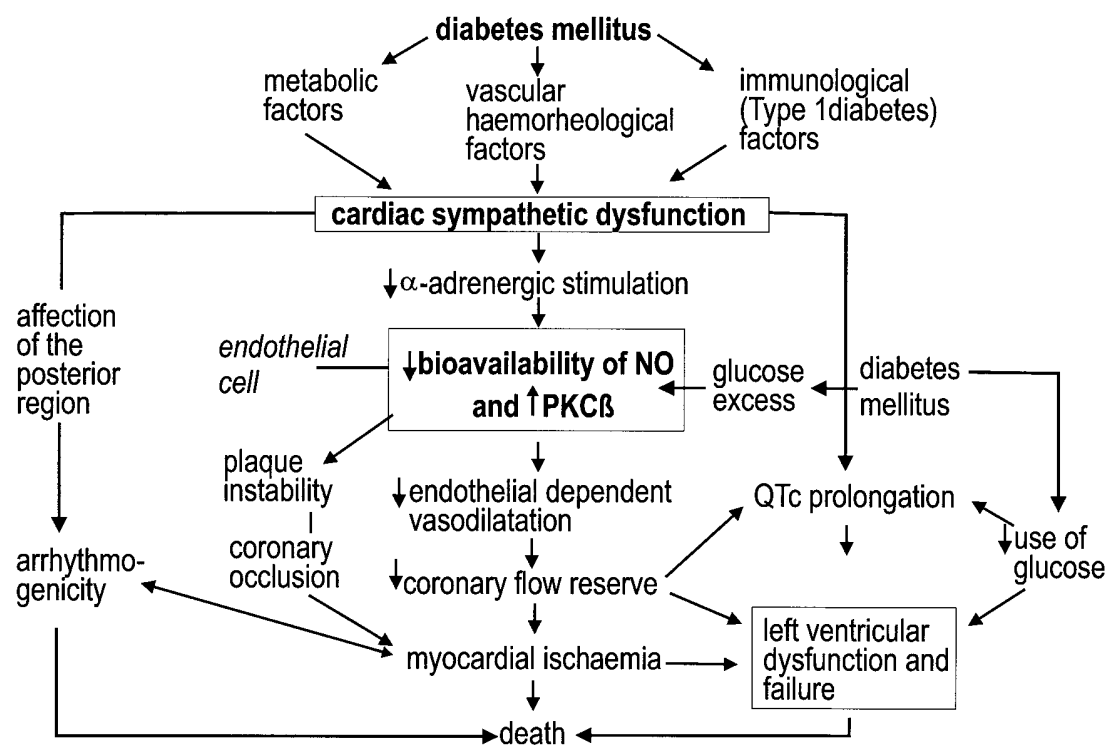

Fig.3. Some of the proposed mechanisms leading from early changes to advanced impairment of cardiac function in diabetes

some of the suggested mechanisms highlighted in the review and underlines the intensive interplay between the various pathways.

\section{Sympathetic incompetence}

The balance of activity between the cardiac sympathetic and parasympathetic nervous system has a key role for the functional and structural performance of the diabetic heart [51]. Metabolic [54-57], vascular/ haemorrheological $[56,58]$ and, in Type I diabetes, immunological factors [59-63] are currently hypothesized to contribute to the pathogenesis, which, however, has not been fully explained. The heterogeneous pattern and the high extent of dysfunction of the cardiac sympathetic nervous system in diabetes was largely unknown until advanced scintigraphic techniques for direct characterization of dysfunction of sympathetic neurons in the living heart emerged in the 1990s [48-50, 64-67]. Previously, diagnosis of cardiac sympathetic abnormalities had been based mainly on conventional non-invasive cardiac reflex tests, including measurements of heart rate variation and blood pressure changes $[53,67,68]$. Furthermore, 24-h heart rate variability has been applied to assess cardiac sympathetic dysfunction [69, 70]. These approaches only indirectly assess diabetic cardiac autonomic dysfunction, they do not differentiate absolutely between sympathetic and parasympathetic function and they do not assess the heart regionally $[48,60,64,66,67]$. Imbalance of the activity of the cardiac sympathetic nervous system has been sug- gested to lead to muliple functional disturbances and to increase the risk of arrythmogenicity of the diabetic heart $[48,71]$. In a broader view, data from the Framingham cohort suggested that chronotropic incompetence, i. e. inappropriate low heart rate in response to exercise is one of the most important predictors of premature mortality [72].

\section{Scintigraphically assessed cardiac sympathetic dysfunction}

Advanced single-photon emission computed tomography (SPECT) and positron emission tomography (PET) using radiopharmaceuticals I-123-metaiodobenzylguanidine (I-123-MIBG) and 11C-hydroxyephedrine (11C-HED) enable the characterization of the pattern and extent of cardiac sympathetic dysinnervation [73-75]. The radiolabelled norepinephrine analogues applied have the same active uptake mechanisms as norepinephrine [75-80] with a highaffinity, sodium-dependent intraneuronal uptake mechanism (uptake 1) confined to postganglionary presynaptic sympathetic nerve endings and a lowaffinity extraneuronal uptake mechanism (uptake 2) $[75,76,81]$. Unlike noradreanline, MIBG and HED are metabolized neither by monoaminooxidase nor by catecholamine- $O$-methyltransferase $[64,75,77]$. They are rapidly excreted in the urine in their unmetabolized form [75, 79, 82].

In 1992 the presence of cardiac sympathetic dysinnervation, as assessed by I-123-MIBG scintigraphy, was reported in diabetic patients with autonomic neuropathy [64]. Succeeding scintigraphic investigations characterized the pattern of cardiac sympathetic dysinnervation in diabetes and showed that cardiac sympathetic dysinnervation is present more frequently than previously detected with conventional cardiac reflex tests [48, 50, 65, 66, 83-86]. 


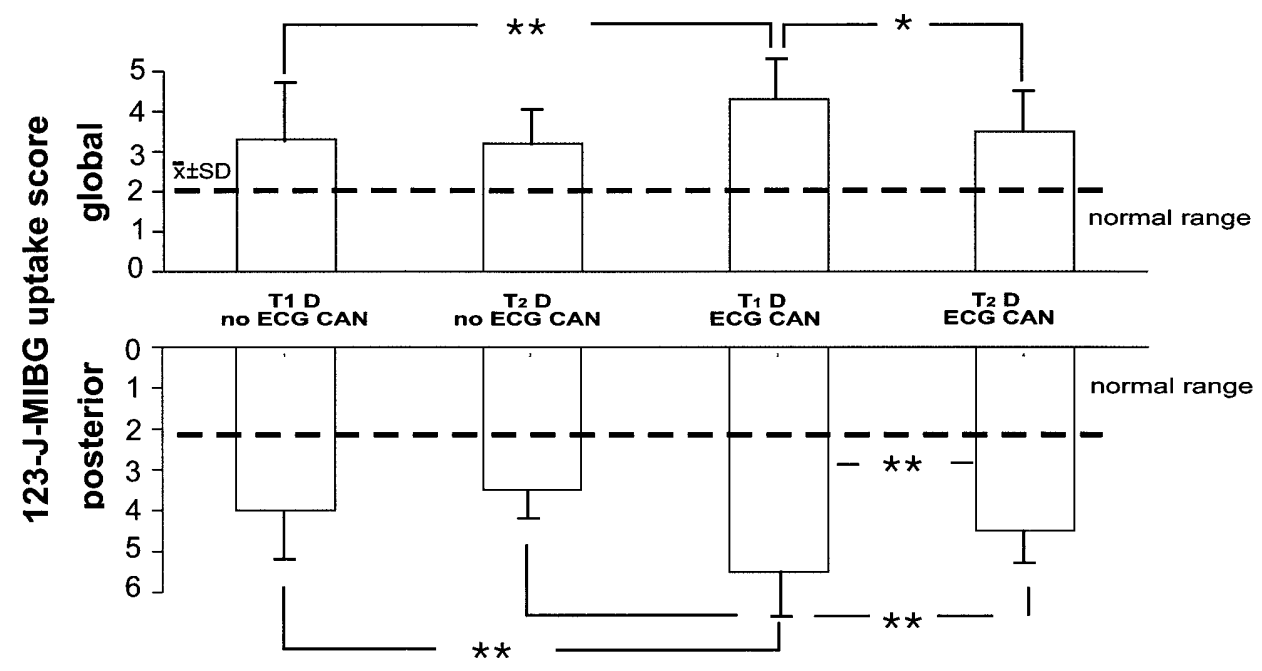

Fig. 4. Global and posterior sympathetic dysfunction of the heart in Type I (TI) and Type II (TII) diabetic patients without ECG-detectable cardiac autonomic neuropathy (ECG CAN) and without detectable myocardial perfusion defects. T1 D no ECG CAN $n=22$, T2 D no ECG CAN $n=15$, T1 D ECG CAN $n=20$, T2 D ECG CAN $n=15$. * $p<0.05, * * p<0.01$ $[48,88]$

Figure 2 depicts the typical pattern of the distribution of myocardial uptake in the diabetic patient with cardiac sympathetic dysinnervation compared with a control subject.

It is important to realize that sympathetic dysinnervation can be present to a large extent at the diagnosis of diabetes, both in Type I and Type II diabetes. Scintigraphically, cardiac sympathetic dysinnervation was detected in $77 \%$ of newly diagnosed metabolically stabilized Type I diabetic patients [50]. Of these patients $9 \%$ have been reported to have advanced cardiac sympathetic dysinnervation, as evidenced by a severe reduction of global I-123-MIBG uptake or no uptake of the radiotracer [50]. The pattern of cardiac sympathetic dysinnervation of newly diagnosed Type I diabetic patients is heterogeneous with a predominant affection of the posterior myocardial region $[48,50]$. Supporting the view that neuronal abnormalities progress with duration of diabetes [87], defects of cardiac sympathetic innervation are more enhanced in long-term than in newly diagnosed Type I diabetic patients $[48,50]$. In long-term diabetic patients, substantial heterogeneity of cardiac sympathetic dysinnervation characterized by a more advanced affection of the posterior myocardium compared with the anterior, lateral and septal myocardium is observed [48].

The superior sensitivity of I-123-MIBG scintigraphy to conventional cardiac reflex tests is underlined by the observation that the majority of newly diagnosed and long-term Type I diabetic patients without ECG-detectable cardiac autonomic neuropathy show cardiac sympathetic dysfunction at scintigraphic investigation $[48,50,65,83]$.

Assessment of the heart by PET with 11C-HED in Type I diabetes confirms the frequent sympathetic dysinnervation and the predominance in the posterior myocardial region [79]. Complicating the heterogeneous cardiac sympathetic dysinnervation, with PET diabetic patients have been shown to have proximal sympathetic hyperinnervation of the heart [52].

In Type II diabetes, although less studied, the pattern of cardiac sympathetic dysinnervation is similar (Fig.4) to that of Type I diabetic patients [66, 88]. There is, however, evidence that the extent of dysinnervation is less pronounced in Type II than in Type I diabetes $[88,89]$.

\section{Autoantibodies against sympathetic ganglia}

In Type I diabetes, immmunological factors, as evidenced by autoantibodies against sympathetic ganglia, have been reported to be associated with cardiac sympathetic dysfunction [59-62, 90-95]. Among Type I diabetic patients $20-35 \%$ have autoantibodies against sympathetic ganglia $[59,61,62]$ and the presence of autoantibodies against sympathetic ganglia has been shown to be related to scintigraphically assessed cardiac sympathetic dysfunction [59] and ECG-based abnormalities of heart rate variation [61]. Autoantibodies against sympathetic ganglia seem to be rather specific for cardioneuropathy of Type I diabetic patients and occur independently of those against islet cells, GAD or protein tyrosine phosphatase-like molecules ICA512 [61]. Autoantibodies against autonomic nervous tissues are not detected to an important extent in Type II diabetes both with and without cardiac sympathetic dysfunction and in patients with neuropathies in non-diabetic neurological diseases $[61,63,96]$. The specificity of autoantibodies against sympathetic ganglia in Type I diabetes support the view that autoantibodies targetted against sympathetic postganglionic 


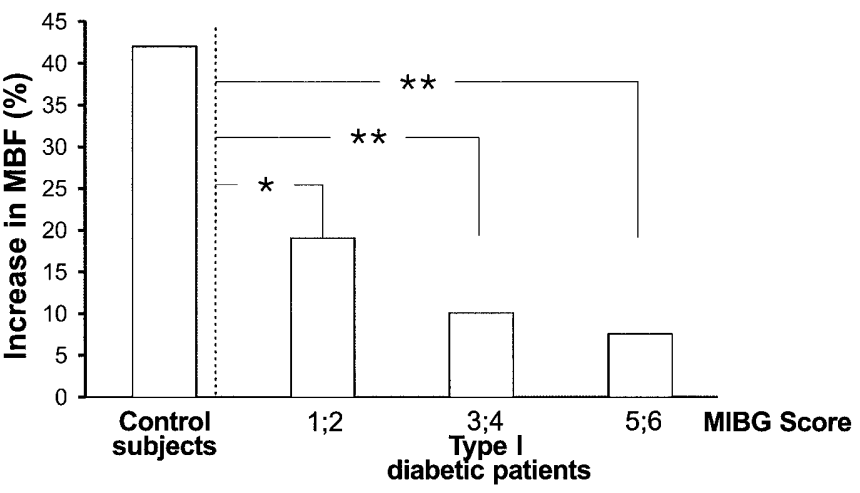

Fig. 5. Increase in myocardial blood flow (MBF) with regard to sympathetic dysfunction in Type I diabetes as assessed with PET and SPECT. Reduction of I-123-MIBG uptake: 1. 2. $=$ mild, 3. $4=$ moderate, 5. 6. severe. Control subjects $n=20$, Type I diabetic patients $n=15$. * $p=0.012$, ** $p<0.001[109]$

neurons cause local damage and subsequently deteriorate neuronal function in the patients.

\section{Endothelial dysfunction}

\section{The role of nitric oxide}

The endothelium is considered to play a key part in maintaining vascular homeostasis of the heart. Multiple endothelium-derived vasoconstrictive and vasodilatory substances, which modulate vascular tone, platelet aggregation and vascular smooth muscle cell proliferation, have been described and reviewed elsewhere [97-99]. The mechanisms leading to endothelial activation and dysfunction in diabetes are, however, not completely understood. One of the best characterized endothelial-derived substances is nitric oxide (NO), which is suggested to largely mediate endothelial-derived vasodilatation [100-102]. Synthesized from the amino acid L-arginine by the endothelium isoform of NO synthase (eNOS) and having a halflife of less than a few seconds, it rapidly traverses the subendothelial space to stimulate smooth muscle cell guanylate cyclase, increasing cyclic-GMP and decreasing intracellular calcium concentrations, and subsequently causing smooth muscle relaxation [103]. The basal release of $\mathrm{NO}$ from endothelial cells induces a constant, active vasodilatory tone, antagonizing vasoconstrictor substances, including angiotensin II, endothelin and vasoconstricting prostaglandines [103]. A decrease of biological NO activity has been observed in patients with risk factors for coronary artery disease and without overt clinical artherosclerosis suggesting a role early in atherogenesis [103, 104].

In the hearts of rats with early diabetes induced by either alloxan or streptozotocin, there is evidence for increased NO formation secondary to increased ac- tivity of NO synthase, which is offset by accelerated inactivation of NO by superoxide anions [105]. In the rat aorta of experimental diabetes, decreased functional NO activity, a diminished response to endothelium-dependent vasodilators and an unchanged response to endothelium-independent vasodilators has been observed [106]. In porcine aortic endothelium, hyperglycaemia has been shown to directly inhibit NO synthase and reduce endothelial cell guanylate cyclase activity [107].

Therefore, it has been hypothesized that a decreased NO release or an increased inactivation of NO by reactive oxygen species is responsible for an impaired endothelium-dependent vasodilator response [106]. Furthermore, NO imbalance might be a major driving force for instability of atherosclerotic plaque in diabetes [108].

\section{Coronary blood flow reserve}

Applying PET technology to measure endothelialdependent blood flow reserve in Type I diabetes, a reduction of coronary blood flow reserve has been detected [109, 110]. Additional assessment of cardiac sympathetic dysfunction with SPECT showed a trend towards an advanced decrease in flow reserve with progression of cardiac sympathetic dysfunction (Fig. 5) [109]. Hypothetically, decreased NO bioavailability secondary to sympathetic dysfunction could account for the effect.

The observations are in line with an increasing number of studies showing reduced coronary blood flow reserve early on in diabetes. Positron emission tomography with $13 \mathrm{~N}$-ammonia, an established method to quantify haemodynamic abnormalities and assess enthothelial-dependent coronary vasodilatatory reserve in humans, has substantially contributed to detection of myocardial perfusion defects [110-112]. The technique is based on the use of 13$\mathrm{N}$-ammonia, which is retained in myocardial tissue in proportion to blood flow. Relative and absolute measures of regional myocardial blood flow can be obtained [111]. Positron emission tomography has been reported to detect coronary artery disease with a sensitivity of $92 \%$ and a specificity of $89 \%$ [98]. Preferably, resting myocardial perfusion scintigraphy is combined with exercise testing to unmask reduced myocardial blood flow reserve [111]. Dipyridamole or adenosine are applied to pharmacologically induce maximum coronary vasodilatation [111]. The cold pressor test assesses myocardial blood flow in response to sympathetic nerve stimulation [113].

Applying PET imaging to diabetic patients, it has been shown that resting myocardial blood flow is not significantly impaired in diabetes [105, 113-115]. Endothelial-dependent coronary flow reserve has, however, been observed as reduced in both Type I and 


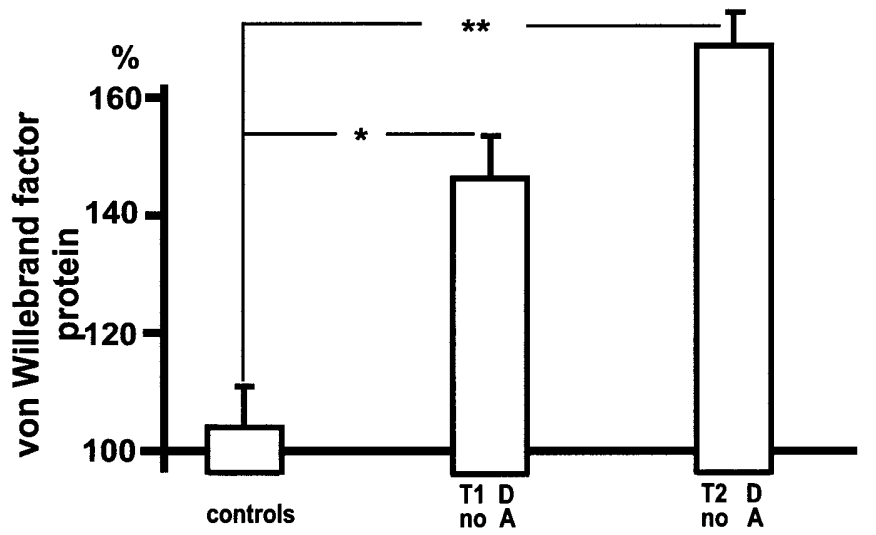

Fig. 6. Early endothelial activation as evidenced by von Willebrand factor protein in Type I and Type II diabetic patients (T1\&2D) without clinically detectable angiopathy (A). Control patients $n=31$, T1 D no A $n=42$, T2 D no A $n=105$. $* p<0.05, * * p<0.01[98,125]$

Type II diabetic patients [109, 113-115]. Recent studies suggest that cardiac sympathetic dysfunction affecting cardiac sympathetic efferent sympathetic signals is directly related to coronary blood flow in diabetes $[109,113,116]$. Sympathetically mediated myocardial blood flow, as induced by cold pressor test, was increased by $31 \%$ in diabetic patients without scintigraphically assessed cardiac sympathetic dysinnervation compared with only $14 \%$ in diabetic patients with cardiac sympathetic dysinnervation [113]. Furthermore, impairment of coronary flow reserve to cold has been shown to be related to the degree of diabetic cardiac sympathetic dysfunction [113]. These observations suggest that cardiac sympathetic dysfunction in diabetes is associated with an impaired coronary blood flow response to sympathetic stimulation, indicating a link between sympathetic nervous defects and alterations of coronary perfusion [113].

This hypothesis is enhanced by the observation that flow reserve in humans is largely independent of changes in haemodynamics and circulating catecholamines [113]. Beta-adrenergic blockade also does not diminish increases in blood flow in normal coronary arteries in response to cold pressure test [117]. Thus increased regional contractility with subsequent enhanced oxygen demand and metabolic vasodilatation is unlikely [113].

Hypothetically, a reduction of sympathetically mediated coronary blood flow in diabetes with cardiac sympathetic dysfunction could directly result from a decrease in endothelium-derived NO activity. Supporting this view, norepinephrine and BHT 920, a selective alpha2 adrenergic receptor agonist, have been reported to increase dose-dependent nitrate release from human coronary microvessels [118].

Therefore, the frequently detectable cardiac sympathetic dysinnervation in the course of diabetes could be associated with subsequent reduction of cor- onary blood flow reserve leading to an impaired vascular performance of the diabetic heart. It is of note that a prolongation of the QTc interval often present in ECG recordings of diabetic patients, seems to be much more related to disordered myocardial blood flow and cardiovascular risk profile than to ECGbased cardioneuropathy $[51,119,120]$. The QTc interval prolongation is also associated with early Type II diabetes and is a strong predictor of cardiac death, e.g. in the Dundee UKPDS cohort [119]. The observation that in Type I diabetes the length of the QTc interval is related to resting myocardial blood flow supports the view [120].

\section{Endothelial cell activation}

Along with early endothelial dysfunction and reduced coronary blood flow reserve, there is also evidence for early endothelial cell activation in diabetes, which might be a major preconditioning factor for occluding arterial thrombus formation and death, especially in connection with NO-driven plaque instability and rupture. Expression of endothelial molecules in response to high glucose concentrations could account for endothelial interaction with leucocytes and monocytes $[121,122]$. In addition, impaired fibrinolytic activity of the endothelium has been suggested [123]. Apart from NO a huge array of substances is released from endothelial cells upon activation, e.g. angiotensin II, endothelin 1 , TGF $\beta$, vascular endothelial growth factor (VEGF), plasminogen activator inhibitor-1, prostaglandins (all of which are presumably important for diabetic vasculopathy) and von Willebrand factor protein which among other effects facilitates platelet adhesion to the vessel wall [124]. Von Willebrand factor protein has been used as a surrogate marker of endothelial cell activation [98]. The 10-year follow-up results of the Munich General Practitioner Project have shown that the concentration of von Willebrand factor protein in plasma is an independent, prospective predictor of macrovascular death in Type II diabetic patients, both with and without detectable macrovascular disease at baseline [125]. Increased concentrations of von Willebrand factor protein have been found in cohorts of Type I as well as Type II diabetic patients free of angiopathy as evidenced by normal results of a vascular check-up including ECG, ultrasound of the carotid and peripheral arteries, funduscopy and screening for microalbuminuria (Fig.6). Plasma concentrations of von Willebrand factor protein are also closely correlated with ADP-induced platelet aggregation in vitro [98]. 


\section{The role of Protein kinase $C$}

Protein kinase C, a cytoplasmic, calcium-activated, phospholipid-dependent kinase, represents a family of serine/threonine-specific protein kinases, which act as an important intracellular transduction system [126]. In diabetes, activation of the diacylglycerol (DAG)-protein kinase C (PKC) pathway induces multiple structural vascular abnormalitites including increased production of extracellular matrix and cytokines, enhancement of contractility, permeability and vascular cell proliferation, activation of cytosolic phospholipase A2 and inhibition of $\mathrm{Na}^{+}-\mathrm{K}^{+}$-ATPase [126-128]. Although the pathways of glycation and advanced glycation end products (AGE) formation as well as the sorbitol pathway evidently have an important role in the pathobiology of diabetic sequelae (presumably more so in the longer run), for the early changes the activation of the protein kinase family, and in particular of PKC $\beta$, could be a key event [126]. In human vascular cells in culture, rather short-lived $(3 \mathrm{~h})$ and not very high $(15 \mathrm{mmol})$ glucose pulses specifically stimulate PKC $\beta$-dependent pathways on a messenger RNA level [129]. Such conditions could easily also apply to the in vivo situation in humans and be relevant in prandial glucose spikes often seen in the early phase of diabetes.

In diabetic animal models activation of PKC isoforms PKC $\beta \mathrm{I}$ and $\beta \mathrm{II}$ have been shown in heart and aortic endothelial and smooth muscle cells [130, 131]. As suggested more recently by observations in cultured retinal microvascular cells, hyperglycaemiainduced PKC up-regulation impairs NO-mediated vasodilatation in diabetes by inhibiting constitutive NO synthase (cNOS) expression [132]. Protein kinase $\mathrm{C}$ has been suggested to regulate renal haemodynamics by increasing or decreasing NO production dependent on cell type, tissue location and duration of diabetes [126, 133, 134]. Activation of PKC $B$ seems to further inhibit NO production and release which is impaired in diabetes.

Transgenic mice specifically overexpressing the PKC $\beta$ II isoform in the moycardium develop cardiomyopathy with changes similar to those in diabetes [135]. In failing human hearts, increased expression and activity of calcium-sensitive PKC $\beta \mathrm{I}$ and $\beta \mathrm{II}$ isoforms have been observed [136]. Protein kinase C activation and translocation of certain isoforms also occur in patients with Type II diabetes [137]. Hyperglycaemia has been observed to stimulate both translocation and synthesis of PKC $[137,138]$. Inhibition of PKC $\beta$ by the selective inhibitor LY333531 has been reported to inhibit endothelial cell proliferation, angiogenesis, and permeability induced by VEGF [139]. Protein kinase $\mathrm{C}$ inhibitors also inhibit expression of VEGF in human aortic cells [129].

Based on these observations it could be hypothesized that hyperglycaemia-induced activation of cer- tain isoforms of PKC in diabetes is a link connecting glucose spikes and glucose excess with early changes of sympathetic incompetence, impaired NO release and endothelial dysfunction and activation, i.e. early "ailments", and ultimately with severe damage, such as heart failure, plaque instability, arterial thrombus formation and death (Fig.3). This hypothesis will also become testable in diabetic patients with the advent of PKC-specific and non-toxic inhibitors.

\section{The glycaemic impact on cardiac function}

The excessive risk of cardiovascular complications in diabetes cannot be explained by the pattern of conventional risk factors, although there might be an enormous accumulation of these risk factors at clinical diagnosis of Type II diabetes as well as existing cardiovascular and other macrovascular disease at this point of time [140]. There is evidence that it is the hyperglycaemic state itself, which predispoes to impairment of cardiac function and to an excessive cardiovascular risk $[141,142]$. Even preprandial and postprandial glucose concentrations within the non-diabetic range have been reported to be associated with an increased risk for cardiovascular events, as more recently outlined by a meta-analysis of 20 prospective studies comprising over 95000 people who had 3707 cardiovascular events over 12.4 years [141]. Compared with a glucose concentration of $4.2 \mathrm{mmol} / 1$, a fasting glucose concentration of $6.1 \mathrm{mmol} / \mathrm{l}$ and a 2 -h glucose concentration of $7.8 \mathrm{mmol} / \mathrm{l}$ was associated with a relative risk of cardiovascular events of 1.33 and 1.58 [141]. Comparison of the American Diabetes Association (ADA) fasting glucose criteria and the World Health Organisation (WHO) 2-h post-challenge glucose criteria in the DECODE study showed that high blood glucose concentrations $2 \mathrm{~h}$ after load are associated with an increased risk of deaths, independently of fasting blood glucose [142]. As previously reviewed, numerous prospective studies with follow-up lengths from 3.5 to 10 years show an association between glycaemic control and cardiovascular events in diabetes [143]. The risk of cardiovascular death has been reported to be increased by 4.3 -fold over 3.5 years in Type II diabetic patients with a mean $\mathrm{HbA}_{1 \mathrm{c}}$ value above $7 \%$ compared with those with a mean $\mathrm{HbA}_{1 \mathrm{c}}$ value less than $7 \%$ [144]. The Munich General Practitioner Project, a 10-year prospective study, confirmed that $\mathrm{HbA}_{1 \mathrm{c}}$ is an independent risk factor for cardiovascular mortality in diabetes [125].

\section{Primary prevention of cardiac dysfunction}

Two large prospective intervention studies in diabetes, the DCCT study for Type I and the UKPDS study for Type II diabetes, investigated the effect of glycae- 
mia on prevention of cardiovascular complications and proved glycaemic control contributes to a reduction in cardiac abnormalities [33, 34, 145-147]. In the group that received intensive therapy in the DCCT study (mean $\mathrm{HbA}_{1 \mathrm{c}} 7.2 \%$ ), abnormalities of heart rate variation occurred less frequently $(5 \%)$ than in the cohort with conventional therapy $(9 \%$, mean $\mathrm{HbA}_{1 \mathrm{c}} 8.9 \%$ ) $[145,146]$. A non-significant reduction of macrovascular events in the intensive therapy group ( 23 vs 40 events) during the follow-up period was noted. The cardiovascular risk profile was reduced in the intensive therapy group [146]. As observed in the DCCT study, the UKPDS study failed to show a reduction of macrovascular events in Type II diabetes [33, 34, 147]. Intensive therapy compared with conventional therapy (mean $\mathrm{HbA}_{1 \mathrm{c}} 7.0 \%$ vs $7.9 \%$ ) resulted in only a borderline reduction $(p=0.052)$ in the occurrence of myocardial infarction by $16 \%$. In both studies, hyperglycaemia might not have been controlled well enough by intensive therapy to reduce cardiovascular end points. As already stated, the concept has been put forward that the association of cardiovascular disease with plasma glucose concentration starts in the high normal "dysglycaemic" range below the cut-off for overt diabetes.

In Type II diabetes, the progression to cardiac autonomic dysfunction can be reduced by mulifactorial intervention including optimization of metabolic control and treatment of hypertension, microalbuminuria and dyslipidaemia [148]. This approach has been shown to reduce the occurrence of cardiac autonomic neuropathy by $69 \%$ [148].

\section{Secondary prevention of cardiac dysfunction}

As evidenced by the DIGAMI study, the poor prognosis in diabetic patients with acute myocardial infarction can be improved by improvement of metabolic control [149-151]. In that study, 620 diabetic patients with acute myocardial infarctions were assigned at random to either 24-h glucose-insulin infusion succeeded by multiple insulin injections or conventional therapy. Although metabolic control was similar at admission $(15.7 \pm 4.2 \mathrm{vs} 15.4 \pm 4.1 \mathrm{mmol} / \mathrm{l})$, patients receiving glucose-insulin infusion had better metabolic control after $24 \mathrm{~h}$ and at discharge ( $9.6 \mathrm{mmol} / \mathrm{l}$ vs $11.7 \mathrm{mml} / \mathrm{l} ; 8.2 \mathrm{mmol} / \mathrm{l}$ vs $9.0 \mathrm{mmol} / \mathrm{l}$ ). These differences in glucose control translated into differences of $\mathrm{HbA}_{1 \mathrm{c}}$ values at 3 months which were also maintained at 1-year follow-up. Mean $\mathrm{HbA}_{1 \mathrm{c}}$ values close to $7 \%$ could be achieved in the insulin infusion group. During their stay in hospital, mortality was reduced in diabetic patients, who had not been treated previously with insulin and had a low cardiovascular risk profile. In patients who had received glucose-insulin infusion, 1-year mortality was reduced from $26 \%$ to $19 \%$ and mortality at 3.4 years from $44 \%$ to $33 \%$ [150], substantiating a relative risk reduction of $30 \%$ and $28 \%$ [149-151].

In the ECLA pilot trial, which assessed the effect of a glucose-insulin-potassium-infusion in patients with acute myocardial infarction, a non-significant reduction in hospital events in patients allocated to glucose-insulin-potassium-infusion and a reduction in mortality in patients additionally treated with reperfusion strategies was observed [152].

In newly diagnosed, metabolically stabilized Type I diabetic patients, improvement of metabolic control to near-normoglycaemia with intensive insulin therapy has been observed to result in a reduction of cardiac sympathetic dysinnervation in the posterior and septal myocardial region at 1-year follow-up [85]. Of the diabetic patients $69 \%$ still had cardiac sympathetic defects at 1 year [85]. In poorly controlled long-duration Type I diabetic patients with mean $\mathrm{HbA}_{1 \mathrm{c}}$ values over $11 \%$, substantial improvement of metabolic control (mean $\mathrm{HbA}_{1 \mathrm{c}} 7.3 \%$ at 1 year) partially restores global and anterior, posterior and septal cardiac sympathetic innervation [86]. In contrast, improvement of metabolic control to only a mean $\mathrm{HbA}_{1 \mathrm{c}}$ of $9.8 \%$ did not reduce cardiac sympathetic dysinnervation [86]. In long-duration Type I diabetic patients with average $\mathrm{HbA}_{1 \mathrm{c}}$ values of $8 \%$, scintigraphically assessed cardiac sympathetic dysinnervation neither regressed nor progressed during a 3-year follow-up [84]. Values of $\mathrm{HbA}_{1 \mathrm{c}}$ of less than $7.6 \%$ over a 4year period have been shown to prevent progression of scintigraphically assessed cardiac sympathetic dysfunction in Type I diabetic patients [153].

Other than for scintigraphically assessed cardiac sympathetic disturbances, there is evidence that ECG-based cardiac autonomic abnormalities are largely irreversible with improvement of metabolic control $[154,155]$. Successsful pancreatic and kidney transplantation with subsequent near-normal longterm metabolic control did not improve heart rate variation at rest 2 to 3 years after transplantation [155]. Heart rate variation during deep breathing has been reported to remain unchanged in pancreas transplant recipients, whereas a tendency towards improved Valsalva ratio was noted [156].

Observations support the view that a propensity of the cardiac sympathetic nervous system to metabolically induced restoration exists in diabetes. Thus, a metabolically reversible functional component and an irreversible structural component of cardiac sympathetic abnormalities in diabetes is suggested.

\section{Perspectives}

The heart in diabetes requires specific attention and probably warrants a long-term combined endocrinological-cardiological treatment approach. Some unique features targetting the heart in diabetes have 
been unravelled in recent years, in particular cardiac sympathetic dysfunction and incompetence in conjunction with effects driven by the excess of glucose and glucose spikes on the endothelium of large blood vessels that lead to a disordered coronary blood flow reserve. These changes occur early, are often overlooked because of their subtlety, yet predispose arteriosclerotic plaques to instability and rupture and the heart to failure through ischaemia-induced remodelling. It is the early ailments that are accessible to multifactorial treatment including near-normalisation of glycaemia but also in acute coronary syndrome rapid compensation of glucose control by insulin treatment seems to be a key issue on top of cardiological intervention. There are tools to prevent the heart in diabetes from converting from ailing to failing. Quality documentation and registration of the endocrinological and cardiological therapy of diabetic patients with cardiac disease should provide these patients with the best care available.

\section{References}

1. Löwel H, Koenig W, Engel S, Hörmann A, Keil U (2000) The impact of diabetes mellitus on survival after myocardial infarction. Can it be modified by drug treatment? Results of a population-based myocardial infarction register follow-up study. Diabetologia 43: 218-226

2. Folsom AR, Szklo M, Stevens J, Liao F, Smith R, Eckfeldt JH (1997) A prospective study of coronary heart disease in relation to fasting insulin, glucose, and diabetes. Diabetes Care 20: 935-942

3. Lundberg V, Stegmayr B, Asplund K, Eliasson M, Huhtasaari F (1997) Diabetes as a risk factor for MI: population and gender prespectives. J Intern Med 241: 485-492

4. Abbud Z, Shindler D, Wilson A, Kostis J (1995) Effect of diabetes mellitus on short- and longterm mortality rates of patients with acute myocardial infarction: a statewide study. Am Heart J 130: 51-58

5. Orlander PR, Goff DC, Morrissey M et al. (1994) The relation of diabetes to the severity of acute myocardial infarction and postmyocardial infarction survival in Mexican-Americans and non-Hispanic whites: the Corpus Christi Heart Project. Diabetes 43: 897-902

6. Woodfield SC, Lundbergan CF, Reiner JS et al. (1996) Angiografic findings and outcome in diabetic patients treated with thrombolytic therapy for acute myocardial infarction: the GUSTO-I experience. J Am Coll Cardiol 28: $1661-1669$

7. Miettinen H, Haffner SM, Lehto S et al. (1998) Impact of mortality after the first myocardial infarction. Diabetes Care 21: 69-75

8. Donahue RP, Orchard TJ (1992) Diabets mellitus and macrovascular complications. An epidemiological perspective. Diabetes Care 15: 1141-1155

9. Panzram G (1987) Mortality and survival in Type II (noninsulin-dependent) diabetes mellitus. Diabetologia 30: 123-131

10. Stamler J, Vaccarro O, Neaton J, Wentworth D (1993) Diabetes, other risk factors, and 12 year cardiovascular mortality for men screened for the Multiple Risk Factor Intervention Trial. Diabetes Care 16: 434-449
11. Bell DS (1995) Diabetic cardiomyopathy: a unique entity or a complication of coronary artery disease? Diabetic Care 18: 708-714

12. Aronson D, Rayfield EJ, Chesbro JH (1997) Mechanisms determining course and outcome of diabetic patients who have had acute myocardial infarction, Ann Intern Med 126: 296-306

13. Raman M, Nesto RW (1996) Heart disease in diabetes mellitus. Endocrinol Metab Clin North Am 25: 425-438

14. Mahgoub MA, Abd-Elfattah AS (1998) Diabetes mellitus and cardiac function. Mol Cell Biochem 180: 59-64

15. Haffner SM, Lehto S, Rinönnemaa T, Pyörälä K, Laakso M (1998) Mortality from coronary heart disease subjects with Type II diabetes and in non-diabetic subjects with and without prior MI. N Engl J Med 339: 229-234

16. Thoelke H, Meusel K (1994) Zur Überlebensdauer von Typ-II-Diabetikern. Ergebnisse einer 20 jährigen Followup-Studie in Berlin Ost. Senatsverwaltung für Gesundheit Berlin, Diskussionsbeiträge zur Gesundheitsforschung 19: 1-33

17. Löwel H, Stieber J, Koenig W et al. (1999) The diabetesrelated risk of MI in a Southern German population: results of the MONICA Augsburg studies 1985-1994. Diab Stoffw 8: 11-21

18. Granger CB, Califf RM, Young S et al. (1993) Outcome of patients with diabetes mellitus and acute myocardial infarction treated with thrombolytic agents J Am Coll Cardiol 21: 920-925

19. Stein B, Weintraub WS, Gebhart SP et al. (1995) Influence of diabetes mellitus on early and late outcome after percutaneous transluminal coronary angioplasty. Circulation 91: 979-989

20. Holmes DR, Vliestra RE, Smith HC et al. (1984) Restenosis after percutaneous transluminal angioplasty (PTCA): a report from the PTCA registry of the National Heart, Lung and Blood Institute. Am J Cardiol 53: 77C$81 \mathrm{C}$

21. Van Belle E, Banters C, Hubert E et al. (1997) Restenosis rates in diabetic patients: A comparison of coronary stenting and ballon angioplasty in native coronary vessels. Circulation 96: 1454-1460

22. Maynard C, Chapko M, Every NR, Martin DC, Ritchie JL (1998) Coronary angioplasty outcomes in the Healthcare Cost and Utilization Project 1993-1994. Am J Cardiol 81: 848-852

23. Carozza JP, Kuntz RE, Fishman RF, Bains DS (1993) Restenosis after arterial injury caused by stenting in patients with diabetes mellitus. Ann Intern Med 118: 344-349

24. Kastrati A, Schömig A, Elezi S et al. (1997) Predictive factors of restenosis after coronary stent placement. J Am Coll Cardiol 30: 1428-1436

25. Kleiman NS, Lincoff AM, Kereiakes DJ et al. (1998) Diabetes mellitus, glycoprotein IIb/IIIa blockade, and heparin: evidence for a complex interaction in a multicenter trial. Epilog investigators. Circulation 97: 19121920

26. Weintraub WS, Stein B, Kosinski A et al. (1998) Outcome of coronary bypass surgery versus coronary angioplasty in diabetic patients with mulitivessel coronary artery disease. J Am Coll Cardiol 31: 10-19

27. The Bypass Angioplasty Revascularisation Investigation (BARI) Investigators (1996) Comparison of coronary bypass surgery with angioplasty in patients with multivessel disease. N Engl J Med 335: 217-225

28. Rao V, Ivanov J, Weisel RD et al. (1996) Predictors of low cardiac output syndrome after coronary artery bypass. J Thorac Cardiovasc Surg 112: 38-51 
29. O'Keefe JH, Blackstone EH, Sergeant P, McCallister BD (1998) The optimal mode of coronary revascularisation for diabetics. A risk-adjusted long-term study comparing coronary angioplasty and coronary bypass surgery. Eur Heart J 19: 1696-1703

30. Kornowski K, Mintz GS, Kent AD (1997) Increased restenosis in diabetes mellitus after coronary interventions is due to exaggerated intimal hyperplasia: a serial intravascular ultrasound study. Circulation 95: 1366-1369

31. Borch-Johnson K, Kreiner S (1987) Proteinuria: value as predictor of cardiovascular mortality in insulin-dependent diabetes mellitus. BMJ 294: 1651

32. Tuomilehto J, Borch Johnson K, Molarius A et al. (1998) Incidence of cardiovascular disease in Type I (insulin-dependent) diabetic patients with and without diabetic nephropathy in Finland. Diabetologia 41: 784-790

33. UKPDS Group (1998) Intensive blood glucose control with sulfonylureas or insulin compared with conventional treatment and risk of complications in patients with type 2 diabetes (UKPDS 33). Lancet 352: 837-853

34. UKPDS Group (1998) Tight blood pressure control and risk of complications in macrovascular and microvascular complications in type 2 diabetes: UKPDS 38. BMJ 317: 703-713

35. Hansson L, Zanchetti A, Carruthers SG et al. (1998) Effects of intensive blood-pressure lowering and low-dose aspirin in patients with hypertension: principal results of the Hypertension Optimal Treatment (HOT) randomised trial. HOT Study Group. Lancet 351: 1755-1762

36. Staessen JA, Thijs L, Gasowski J, Cells H, Fagard RH (1998) Treatment of isolated hypertension in the elderly: further evidence from the systolic hypertension in Europe (Syst-Eur) trial. Am J Cardiol 82: 20R-22R

37. Black HR (1999) Isolated hypertension in the elderly: lessons from clinical trials and future directions. J Hypertens 15: S49-S54

38. HOPE Study Investigators (1999) Effects of an angiotensin-converting-enzyme inhibitor, ramipril, on cardiovascular events in high-risk patients. N Engl J Med 342: $145-153$

39. HOPE Study Investigators (2000) Effects of ramipril on cardiovascular and microvascular outcomes in people with diabetes mellitus: results of the HOPE study and MICRO-HOPE substudy. Lancet 355: 253-259

40. Pyorälä K, Pedersen TR, Kjekshus J, Faergeman O, Olsson AG, Thorgeirsson G (1997) Cholesterol lowering with simvastatin improves prognosis of diabetic patients with coronary disease. A subgroup analysis of the Scandinavian Simvastatin Survival Study (4S). Diabetes Care 20: 614-620

41. Goldberg RB, Mellies MJ, Sacks FM et al. (1998) Cardiovascular events and their reduction with pravastatin in diabetic and glucose-intolerant myocardial infarction survivors with average cholesterol levels: subgroup analyses in the cholesterol and recurrent events (CARE) trial. The Care investigators. Circulation 98: 2513-2519

42. Fava S, Azzopardi J, Muscat HA, Fenech FF (1993) Factors that influence outcome in diabetic subjects with myocardial infarction. Diabetes Care 16: 1615-1618

43. Meier IJ, Klamann A, Heimesaat M, Sarfert P, Schmiegel W, Nauck M (2000) Predictors of a lethal outcome of myocardial infarctions in patients with type-2-diabtes mellitus. Diab Stoffw 9: 149-155

44. Iwasaka T, Kimura Y, Takahashi N et al. (1992) Residual left ventricular pump function after acute myocardial infarction in NIDDM patients. Diabetes Care 15: $1522-1526$
45. Jaffe AS, Spadaro JJ, Schechtman K et al. (1984) Increased congestive heart failure after myocardial infarction of modest extent in patients with diabetes mellitus. Am Heart J 108: 31-37

46. Stefanidis A, Melidonis A, Dosios T et al (2000) Enhanced myocardial performance with intensive insulin treatment during acute coronary events. Diabetologia 43: [Suppl 1] Abstract

47. Opie L (1975) Metabolism of free fatty acids, glucose and catecholamines in acute myocardial infarction: relation to myocardial ischemia and infarct size. Am J Cardiol 36: 938-953

48. Schnell O, Kirsch C-M, Stemplinger J, Haslbeck M, Standl E (1995) Scintigraphic evidence for cardiac sympathetic dysinnervation in long-term Type I diabetic patients with and without ECG-based autonomic neuropathy. Diabetologia 38: 1345-1352

49. Lange A, Freeman MR, Josse RG, Armstrong PW (1995) Metaiodobenzylguanidine imaging in diabetes mellitus: Assessment of cardiac sympathetic denervation and its relation to autonomic dysfunction and silent myocardial ischemia. J Am Coll Cardiol 25: 610-618

50. Schnell O, Muhr D, Weiss M, Dresel S, Haslbeck M, Standl E (1996) Reduced myocardial ${ }^{123}$ I-metaiodobenzylguanidine uptake in newly diagnosed IDDM patients. Diabetes 45: 801-805

51. Schnell O, Haslbeck M, Standl E (1996) On the significance of new diagnostic approaches to cardiac autonomic neuropathy in Type 1 diabetes. Diab Stoffw 5: 127-134

52. Stevens MJ, Raffel DM, Allman KC et al. (1998) Cardiac sympathetic dysinnervation in diabetes. Circulation 98: 961-968

53. Strian F, Haslbeck M (1999) Neurologische Erkrankungen: In Diabetologie in Klinik und Praxis. In: Mehnert H, Schoeffling K, Standl E, Usadel KH (eds) 4th edn. Thieme, Stuttgart/New York, pp 456-480

54. Dyck PJ, Zimmerman BR, Tadd HV et al. (1988) Nerve glucose, fructose, sorbitol, myo-inositol and fibre degeneration and regeneration in diabetic autonomic neuropathy. N Engl J Med 316: 542-548

55. Brownlee M, Cerami A, Vlassara H (1988) Advanced glycosilation end products in tissue and the biochemical basis of diabetic complications. N Engl J Med 318: $1315-1321$

56. Cameron NE, Cotter MA (1997) Metabolic and vascular factors in the pathogenesis of diabetic neuropathy. Diabetes 46 [Suppl 2]: S31-S37

57. Tomlinson DR (1999) Mitogen-activated protein kinases as glucose transducers for diabetic complications. Diabetologia 42: 1271-1281

58. Tesfaye S, Malik R, Ward JD (1994) Vascular factors in diabetic neuropathy. Diabetologia 37: 847-854

59. Schnell O, Muhr D, Dresel S et al. (1996) Autoantibodies against sympathetic ganglia and evidence of cardiac sympathetic dysinnervation in newly diagnosed and longterm IDDM patients. Diabetologia 39: 970-975

60. Muhr D, Mollenhauer U, Ziegler AG, Haslbeck M, Standl E, Schnell O (1997) Autoantibodies to sympathetic ganglia, GAD, or tyrosine phosphatase in long-term IDDM with and without ECG-based cardiac autonomic neuropathy. Diabetes Care 20: 1009-1012

61. Muhr-Becker D, Ziegler AG, Druschky A et al. (1998) Evidence for specific autoimmunity against sympathetic and parasympathetic nervous tissues in Type 1 diabetes mellitus and the relation to cardiac autonomic dysfunction. Diabet Med 15: 476-472 
62. Ejskjaer N, Arif S, Dodds W et al. (1999) Prevalence of autoantibodies to autonomic nervous tissue structures in Type 1 diabetes mellitus. Diabet Med 16: 544-549

63. Schnell O, Schwarz A, Muhr-Becker D, Standl E (2000) Cardiac autonomic dysfunction: No association with autoantibodies against autonomic nervous tissues. Exp Clin Endocrinol Diabetes 108: 181-186

64. Mäntysaari M, Kuikka J, Mustonen J et al. (1992) Noninvasive detection of cardiac sympathetic nervous dysfunction in diabetic patients using (123I) metaiodobenzylguanidine. Diabetes 41: 1069-1075

65. Kreiner G, Wolzt M, Fasching P et al. (1995) Myocardial $\mathrm{m}(123 \mathrm{I})$ iodobenzylguanidine scintigraphy for the assessement of adrenergic cardiac innervation in patients with IDDM. Diabetes 44: 543-549

66. Langer A, Freeman MR, Josse RG, Armstrong PW (1995) Metaiodobenzylguanidine imaging in diabetes mellitus: Assessment of cardiac sympathetic dysinnervation and its relation to autonomic dysfunction and silent myocardial ischemia. J Am Coll Cardiol 25: 610-618

67. Spallone V, Menzinger G (1997) Diagnosis of cardiovascular autonomic neuropathy in diabetes. Diabetes 46 [Suppl 2]: S67-S76

68. Ewing DJ, Clarke BF (1982) Diagnosis and management of diabetic autonomic neuropathy. BMJ 285: 916-918

69. Stys A, Stys T (1998) Current clinical applications of heart rate variability. Clin Cardiol 21: 719-724

70. Eckberg DL (1997) Sympathovagal balance: a critical appraisal. Circulation 96: 3224-3232

71. Weston PJ, Gill GV (1999) Is undetected autonomic dysfunction responsible for sudden death in type 1 diabetes mellitus? The 'dead in bed' syndrome revisited. Diabetic Med 16: 626-631

72. Lauer MS, Okin PM, Larson MG, Evans JC, Levy D (1996) Impaired heart rate response to graded exercise. Prognostic implications of chronotropic incompetence in the Framingham Heart Study. Circulation 93: 1520-1526

73. Kline RC, Swanson DP, Wieland DM et al. (1981) Myocardial imaging in man with I-123-metaidobenzylguanidine. J Nucl Med 22: 129-132

74. Sisson MJ, Shapiro B, Meyers L et al. (1987) Metaiodobenzylguanidine to map scintigraphically the adrenergic nervous system in man. J Nucl Med 28: 1625-1636

75. DeGrado TR, Hutchinsons GD, Toorongian SA, Wieland DM, Schwaiger M (1993) Myocardial kinetics of carbon11-meta-hydroxyephedrine (HED): retention mechanisms and effects of norepinephrine. J Nucl Med 34: 1287-1293

76. Tobes MC, Jaques S, Wieland DM, Sisson JC (1985) Effect of uptake-one inhibitors on the uptake of norepinephrine and metaiodobenzylguanidine. J Nucl Med 26: 897-907

77. Wellman HN, Zipes DP (1990) Cardiac sympathetic imaging with radioionated metaiodobenzylguanidine (MIBG). Progress in Cardiology 3/1. In: Zipes DP, Rowlands DJ (eds) Lea and Febiger, Philadelphia, London, pp 161-174

78. Dae MW (1994) Imaging of myocardial sympathetic innervation with metaiodobenzylguanidine. J Nucl Cardiol 1: $23-30$

79. Allman KC, Stevens MJ, Wieland DM et al. (1993) Noninvasive assessment of cardiac diabetic neuropathy by C11 hydroxyephedrine and positron emission tomography. J Am Coll Cardiol 22: 1425-1432

80. Kirsch C-M, Moser E, Buell U (1985) Quantitative Auswertung von 201Tc-Myocardsszintigrammen in SPECT. Nuc Compact 16: 230-234

81. Iversen LL (1971) Role of transmitter uptake mechanisms in synaptic neurotransmission. Br J Pharmacol 41: 571-591
82. Mangner TJ, Tobes MC, Wieland DM, Sisson JC, Shapiro B (1986) Metabolism of iodine-131-metaiodobenzylguanidine in patients with metastatic pheochromocytoma. J Nucl Med 27: 37-44

83. Claus D, Feistel H, Brunhölzl C, Platsch G, Neundörfer B, Wolf F (1994) Investigation of parasympathetic and sympathetic cardiac innervation in diabetic neuropathy. Clin Auton Res 4: 117-123

84. Schnell O, Muhr D, Weiss M et al. (1997) Three-year follow-up on scintigraphically assessed cardiac sympathetic denervation in patients with long-term insulin dependent (Type 1) diabetes mellitus. J Diabetes Complications 11: 307-313

85. Schnell O, Muhr D, Dresel S, Weiss M, Haslbeck M, Standl E (1997) Partial restoration of scintigraphically assessed cardiac sympathetic denervation in newly diagnosed patients with insulin-dependent (Type 1) diabetes mellitus at one-year follow-up. Diabet Med 14: 57-62

86. Muhr-Becker D, Weiss M, Tatsch K, Wolfram G, Standl E, Schnell O (1999) Scintigraphically assessed cardiac sympathetic dysinnervation in poorly controlled type 1 diabetes mellitus: One-year follow-up with improved metabolic control. Exp Clin Endocrinol Diabetes 107: 306-312

87. Pfeifer MA, Schumer MP (1995) Perspectives in Diabetes: Clinical trials of diabetic neuropathy: past, present, and future: Diabetes 44: 1355-1361

88. Schnell O, Muhr-Becker D, Hammer K, Tatsch K, Standl E (1999) Unterschiede in der kardialen autonomen Dysinnervation bei Typ-I- und Typ-II-Diabetes. Diab Stoffw 9 [Suppl 1]: 84A Abstract

89. Sima AA, Zhang W, Xu G, Sugimoto K, Guberski O, Yorek MA (2000) A comparison of diabetic polyneuropathy in Type II diabetic BBZDR/Wor rats and in Type I diabetic BB/Wor rats. Diabetologia 43: 786-793

90. Duchen LW, Anjorin A, Watkins PJ, Mackay JD, Chir B (1980) Pathology of autonomic neuropathy in diabetes mellitus. Ann Intern Med 92: 301-303

91. Gilbey SG, Guy RJ, Jones H, Vergani D, Watkins PJ (1986) Diabetes and autonomic neuropathy: an immunological association? Diabet Med 3: 241-245

92. Brown FM, Kamalesh M, Adri MN, Rabinowe SL (1988) Anti-adrenal medullary antibodies in IDDM subjects and subjects at high risk of developing IDDM. Diabetes Care 11: $30-33$

93. Rabinowe SL, Brown FM, Watts M, Kadrofske MM, Vinik AI (1989) Antisympathetic ganglia autoantibodies and postural blood pressure in IDDM subjects of varying duration and patients at high risk of developing IDDM. Diabetes Care 12: 1-6

94. Zanone MM, Peakman M, Purewal T, Watkins PJ, Vergani D (1993) Autoantibodies to nervous structures are associated with autonomic neuropathy in Type I (insulindependent) diabetes mellitus. Diabetologia 36: 564-569

95. Sundkvist G, Lind P, Bergström B, Lilja B, Rabinowe SL (1991) Autonomic nerve antibodies and autonomic nerve function in type 1 and type 2 diabetic patients. J Intern Med 229: 505-510

96. Cachia MJ, Peakman M, Zanone M, Watkins PJ, Vergani (1997) Reproducibility and persistance of neutral and adrenal autoantibodies in diabetic autonomic neuropathy. Diabet Med 14: 461-465

97. Quyyumi AA (1998) Endothelial Function in health and disease: new insights into the genesis of cardiovascular disease. Am J Med 105: 32S-39S

98. Janka HU, Standl E, Schramm W, Mehnert H (1983) Platelet enzyme activities in diabetes mellitus in relation to endothelial damage. Diabetes 32 [Suppl 2]: 47-51 
99. Hopfner RL, Gopalakrishnan V (1999) Endothelin: emerging role in diabetic vascular complications. Diabetologia 42: 1383-1394

100. Palmer RM, Ferrige AG, Moncada S (1987) Nitric oxide release accounts for the biological activity of endothelium-derived relaxing factor. Nature 327: 524-526

101. Sartori C, Scherrer U (1999) Insulin, nitric oxide and the sympathetic nervous system: at the crossroads of metabolic and cardiovascular regulation. $\mathbf{J}$ Hypertens 17: $1517-1525$

102. Chan NN, Vallance P, Colhoun HM (2000) Nitric oxide and vascular responses in Type I diabetes. Diabetologia 43: $137-147$

103. Wilson SH, Celermajer DS (1999) Nitric oxide, cytokines and free radicals in diabetic vascular disease. Diabetes in the new millenium. In: Turtle JR, Kaneko T, Osato S (eds) The Endocrinology and Diabetes Research Foundation of the University of Sydney, Sydney pp 423-432

104. Celermajer DS (1997) Endothelial dysfunction: does it matter? Is it reversible? J Am Coll Cardiol 30: 325-353

105. Rosen P, Ballhausen T, Stockklauser K (1996) Impairment of endothelium dependent relaxation in the diabetic rat heart. Diabetes Res Clin Pract 31 [Suppl]: S143-S155

106. Piper GM, Gross GJ (1988) Oxygen free radicals abolish endothelium-dependent relaxation in diabetic rat aorta. Am J Physiol 255: H825-H833

107. Weisbrod RM, Brown ML, Cohen RA (1993) Effect of elevated glucose on cyclic GMP and eicosanoids produced by porcine aortic endothelium. Arterioscler Thromb 13: 915-923

108. Standl E (1995) Cellular and molecular mechanisms in the macroangiopathy of diabetes. In: Schwartz CJ, Born GV (eds) New horizons in diabetes mellitus \& cardiovascular disease. Current Science, London, pp 124-131

109. Rihl J, Hattori N, Bengel F, Standl E, Schwaiger M, Schnell O (2000) Advanced endothelial dysfunction in type 1 diabetes with autonomic neuropathy. Exp Clin Endocrinol Diabet [Suppl 1]: S122

110. Di Carli MF, Tobes MC, Mangner Tet al. (1997) Effects of cardiac sympathetic innervation on coronary blood flow. N Engl J Med 336: 1208-1215

111. Schwaiger M, Melin J (1999) Cardiological applications of nuclear medicine. Lancet 354: 661-666

112. Fleischmann K, Hunink M, Kuntz K, Douglas P (1998) Exercise echocardiography or exercise SPECT imaging? JAMA 280: 913-920

113. Di Carli MF, Bianco-Batlles D, Landa ME et al. (1999) Effects of autonomic neuropathy on coronary blood flow in patients with diabetes mellitus. Circulation 100: 813-819

114. Pitkänen O-P, Nuutila P, Raitakari OT et al. (1998) Coronary flow reserve is reduced in young men with IDDM. Diabetes 47: 248-254

115. Yokoyama I, Momomura S, Ohtake T et al. (1997) Reduced myocardial flow reserve in non-insulin-dependent diabetes mellitus. J Am Coll Cardiol 30: 1472-1477

116. Stevens MJ, Dayanikli F, Raffel DM et al. (1998) Scintigraphic assessment of regionalized defects in myocardial sympathetic innervation and blood flow regulation in diabetic patients with autonomic neuropathy. J Am Coll Cardiol 31: 1575-1584

117. Zeiher AM, Drexler H, Wollschlager H, Saurbier B, Just H (1989) Coronary vasomotion in response to sympathetic stimulation in humans: importance of the functional integrity of the endothelium. J Am Coll Cardiol 14: 1181-1190

118. Kichuk MR, Seyedi N, Zhang X et al. (1996) Regulation of nitric oxide production in human coronary microvessels and the contribution of local kinin formation. Circulation 94: 44-51

119. Naas AA, Davidson NG, Thompson C et al. (1998) QT and QTc dispersion are accurate predictors of cardiac death in newly diagnosed non-insulin dependent diabetes: cohort study. BMJ 316: 745-746

120. Maier M, Standl E, Schnell O (2000) QTc interval and scintigraphically assessed myocardial perfusion in newly diagnosed and long-term type 1 diabetes mellitus. J Diabetes Complications 14: 90-95

121. Baumgartner-Parzer SM, Wagner L, Pettermann M, Gessl A, Waldhäusl WK (1995) Modulation by high glucose of adhesion molecule expression in cultured endothelial cells. Diabetologia 38: 1367-1370

122. Fasching P, Veitl M, Rohac M, Streli C, Schneider B, Waldhäusl W, Wagner OF (1996) J Clin Endocrinol Metab 81: 4313-4317

123. Lorenzi M, Cagliero E (1991) Pathobiology of endothelial and other vascular cells in diabetes mellitus. Call for data. Diabetes 40: 653-659

124. Janka HU, Standl E, Standl R (1999) Allgemeiner Überblick über die Angiopathien. In: Mehnert $H$, Standl E, Usadel K-H (eds) Diabetologie in Klinik und Praxis, $4^{\text {th }}$ edn. Thieme, Stuttgart, New York, pp 334-372

125. Standl E, Balletshofer B, Dahl B et al. (1996) Predictors of 10-year macrovascular and overall mortality in patients with NIDDM: the Munich General Practioner Project. Diabetologia 39: 1540-1545

126. Meier M, King GL (2000) Protein Kinase C. In: LeRoith D, Tyalor SI, Olefsky JM (eds) Diabetes mellitus - A fundamental and clinical text. $2^{\text {nd }}$ edn. Lippincott Williams \& Wilkins, Philadelphia, pp 1016-1027

127. Nishizuka Y (1992) Intracellular signaling by hydrolysis of phospholipids and activation of protein kinase C. Science 258: 607-614

128. Nishizuka Y (1995) Protein kinase C and lipid signaling for sustained cellular responses. FASEB J 9: 484-496

129. Williams B, Gallacher B, Patel H, Orme C (1997) Glucose-induced protein kinase $\mathrm{C}$ activation regulates vascular permeability factor mRNA expression and peptide production by human vascular smooth muscle cells in vitro. Diabetes 46: 1497-1503

130. Inoguchi T, Battan R, Handler E, Sportsman JR, Heath W, King GL (1992) Preferential elevation of protein kinase $\mathrm{C}$ isoform $\beta \mathrm{II}$ and diacylglycerol levels in the aorta and heart of diabetic rats: Differential reversibility to glycemic control by islet cell transplantation. Proc Natl Acad Sci USA 89: 11059-11063

131. Xia P, Inoguchi T, Kern TS, Engerman RL, Oates PJ, King GL (1994) Characterization of the mechanism for the chronic activation of diacylglycerol-protein kinase $C$ pathway in diabetes and hypergalactosemia. Diabetes 43: 1122-1129

132. Chakravarthy U, Hayes RG, Stitt AW, McAuley E, Archer DB (1998) Constitutive nitric oxide synthase expression in retinal vascular endothelial cells is suppressed by high glucose and advanced glycation end products. Diabetes 47: 945-952

133. Bank N, Aynedjian HS (1993) Role of EDRF (nitric oxide) in diabetic renal hyperfiltration. Kidney Int 43: 1306-1312

134. Craven PA, Studer RK, DeRubertis FR (1995) Impaired nitric oxide release by glomeruli from diabetic rats. Metabolism 44: 695-698

135. Wakasaki H, Koya D, Schuen FJ et al. (1997) Targeted overexpression of protein kinase $\mathrm{C}$ isoform in myocardi- 
um causes cardiomyopathy. Proc Natl Acad Sci USA 94: 9320-9325

136. Bowling N, Walsh RA, Song G et al. (1999) Increased protein kinase $\mathrm{C}$ activity and expression of $\mathrm{Ca} 2+-$ sensitive isoforms in the failing human heart. Circulation 99: 384-391

137. Nagy K, Levy J, Grunberger G (1991) Impaired translocation of protein kinase $\mathrm{C}$ acitivity in human non-insulin-dependent diabetes mellitus. Metabolism 40: 807-813

138. Pirags V, Assert R, Haupt K, Schatz H, Pfeiffer A (1996) Activation of human platelet protein kinase $\mathrm{C}-\beta 2$ in vivo in response to acute hyperglycaemia. Exp Clin Endocrinol Diabetes 104: 431-440

139. Ishii H, Jirousek MR, Koya D et al. (1996) Amelioration of vascular dysfunctions in diabetic rats by an oral PKC inhibitor. Science 272: 728-731

140. Standl E, Stiegler H (1993) Microalbuminuria in a random cohort of recently diagnosed Type II (non-insulin-dependent) diabetic patients living in the Greater Munich Area. Diabetologia 36: 1017-1020

141. Coutinho M, Gerstein HC, Wang Y, Yusuf S (1999) The relationship between glucose and incident cardiovascular events: a metaregression analysis of published data of 20 studies of 95, 783 individuals followed for 12.4 years. Diabetes Care 22: 233-240

142. The DECODE study group (1999) Glucose tolerance and mortality: comparison of WHO and American Diabetes Association diagnostic criteria. Lancet 354: 617-621

143. Laakso M (1999) Hyperglycemia and cardiovascular disease in type 2 diabetes. Diabetes 48: 937-942

144. Kuusisto J, Mykkänen L, Pyörälä K, Laakso M (1994) NIDDM and its metabolic control predict coronary heart disease in elderly subjects. Diabetes 43: 960-967

145. The Diabetes Control and Complications Trial Research Group (1993) The effect of intensive treatment of diabetes on the development and progression of long term complications in insulin-dependent diabetes mellitus. N Engl J Med 329: 977-986

146. The Diabetes Control and Complications Trial Research Group (1995) Effect of intensive diabetes management on macrovascular events and risk factors in the Diabetes Control and Complication Trial. Am J Cardiol 75: 894-903
147. UKPDS Group (1998) Effect of intensive blood glucose control with metformin on complications in overweight patients with type 2 diabetes (UKPDS 34). Lancet 352: 843-865

148. Gaede P, Vedel P, Parving HH, Pedersen O (1999) Intensified multifactorial intervention in patients with type 2 diabetes mellitus and microalbuminuria: the Steno type 2 randomised study. Lancet 353: 617-622

149. Malmberg K, Rydén L, Efendic S et al. (1995) Randomized trial of insulin-glucose infusion followed by subcutaneous insulin treatment in diabetic patients with acute myocardial infraction (DIGAMI Study): Effects on mortality at 1 year. J Am Coll Cardiol 26: 57-65

150. Malmberg K for the DIGAMI Study Group (1997) Prospective randomised study of intensive insulin treatment on long term survival after acute myocardial infarction in patients with diabetes mellitus. BMJ 314: 1512-1515

151. Malmberg K for the DIGAMI Study Group (1999) Glycometabolic state at admission: Important risk marker of mortality in conventionally treated patients with diabetes mellitus and acute moycardial infarction. Circulation 99: 2626-2632

152. Diaz R, Paolasso EA, Piegas LS et al. (1998) Metabolic Modulation of acute myocardial infarction - The ECLA Glucose-Insulin-Potassium Pilot Trial. Circulation 98: 2227-2234

153. Ziegler D, Weise F, Langen KJ et al. (1998) Effect of glycaemic control on myocardial sympathetic innervation assessed by [123I]metaiodobenzylguanidine scintigraphy: a 4-year prospective study in IDDM patients. Diabetologia 41: 443-451

154. The St Thomas's Diabetic Study Group (1986) Failure of improved glycemic control to reverse diabetic autonomic neuropathy. Diabet Med 3: 330-334

155. Nusser J, Scheuer R, Abendroth D, Illner W-D, Land W, Landgraf R (1991) Effect of pancreatic and/or renal transplantation on diabetic autonomic neuropathy. Diabetologia 34: S118-S120

156. Hathaway DK, Abell T, Cardoso S, Hartwig MS, el Gebely S, Gaber AO (1994) Improvement in autonomic and gastric function following pancreas-kidney versus kidneyalone transplantation and the correlation with quality of life. Transplantation 57: 816-822 